\title{
Combined Treatment with Vitamin E and Vitamin C Decreases Oxidative Stress and Improves Fetal Outcome in Experimental Diabetic Pregnancy
}

\author{
JONAS CEDERBERG, C. MARTIN SIMÁN, AND ULF J. ERIKSSON \\ Department of Medical Cell Biology, Uppsala University, Uppsala, Sweden
}

\begin{abstract}
The aim was to investigate whether dietary supplementation of a combination of the two antioxidants, vitamin $\mathrm{E}$ and vitamin $\mathrm{C}$, would protect the fetus in diabetic rat pregnancy at a lower dose than previously used. Normal and streptozotocin-induced diabetic rats were mated and given standard food or food supplemented with either $0.5 \%$ vitamin $\mathrm{E}+1 \%$ vitamin $\mathrm{C}$ or $2 \%$ vitamin $\mathrm{E}+4 \%$ vitamin $\mathrm{C}$. At gestational d 20, gross morphology and weights of fetuses were evaluated. Vitamins $\mathrm{E}$ and $\mathrm{C}$ and thiobarbituric acid reactive substances were measured in maternal and fetal compartments. In addition, protein carbonylation was estimated in fetal liver. Maternal diabetes increased the rate of malformation and resorption in the offspring. High-dose antioxidant supplementation decreased fetal dysmorphogenesis to near normal levels. The low-dose group showed malformations and resorptions at an intermediate rate between the untreated and the high-dose groups. Thiobarbituric acid reactive substances were increased in fetal livers of diabetic rats and reduced to normal levels already by low-dose antioxidative treatment. Pro-
\end{abstract}

\section{ABSTRACT}

tein carbonylation rate was also increased in fetal liver of diabetic rats; it was normalized by high-dose treatment but only partially reduced by low-dose antioxidants. We conclude that combined antioxidative treatment with vitamins $\mathrm{E}$ and $\mathrm{C}$ decreases fetal malformation rate and diminishes oxygen radicalrelated tissue damage. However, no synergistic effect between the two antioxidants was noted, a result that may influence future attempts to design antiteratogenic treatments in diabetic pregnancy. Oxidatively modified proteins may be teratogenically important mediators in diabetic embryopathy. (Pediatr Res 49: 755-762, 2001)

$\mathbf{N}$, normal (nondiabetic)

MD, manifestly diabetic (i.e. plasma glucose $>20 \mathrm{mM}$ )

STZ, streptozotocin

TBARS, thiobarbituric acid reactive substances

ROS, reactive oxygen species
Maternal type-1 diabetes during pregnancy causes an increased rate of malformation in the fetus despite insulin treatment and glucose monitoring (1-3). The incidence of fetal malformations in type-1 diabetic pregnancies is estimated to be $5-10 \%$ in recent studies $(4-8)$. Several clinical studies have demonstrated that high maternal $\mathrm{HbAlc}$ levels during early pregnancy are associated with an increased risk for malformations $(4,9,10)$. It is, however, likely that the pathogenesis of diabetic embryopathy is multifactorial (11), and in experimental work not only maternal serum levels of glucose but also levels of triglycerides, $\beta$-hydroxybutyrate, branched-chain amino acids, and creatinine correlate positively with increased

Received December 16, 1999; accepted May 22, 2000.

Correspondence and reprint requests: Jonas Cederberg, Uppsala University, Department of Medical Cell Biology, Box 571, BMC, 75123 Uppsala, Sweden; e-mail: jonas.cederberg@medcellbiol.uu.se

Supported by The Ernfors Family Fund, The Swedish Diabetes Association, The Söderberg Foundation, The Novo Nordisk Foundation, and The Swedish Medical Research Council (grant 12X-7475 and 12X-109). resorption and malformation rates (12). Also, genetic factors may predispose for the development of malformations in maternal diabetes $(13,14)$.

The putative role of ROS in the development of diabetic complications has been investigated for several decades (1517). Evidence of ROS involvement in hyperglycemia-induced embryopathy was first obtained in studies in which antioxidant enzymes proved to be protective in vitro $(18,19)$. Increased ROS production $(20,21)$ and lipid peroxidation (22) have subsequently been found in rat embryos cultured in high glucose and in embryos of diabetic rat mothers. Enzymatically produced ROS can disturb embryo development in vitro similarly to the effect of high glucose (23), and the resulting maldevelopment can be blocked by vitamins $\mathrm{E}$ and $\mathrm{C}$ separately (24). Apart from increased production, the putative ROS excess can be attributed to impaired embryonic defense in response to an oxidative environment. This notion is supported by findings of decreased activity and impaired mRNA response 
to maternal diabetes of the radical scavenging enzyme catalase in embryos of a malformation-prone rat strain $(25,26)$

The increased malformation rate in children of mothers with diabetes, despite intense insulin treatment, has raised the question whether adjunct treatments should also be used to further improve fetal outcome. Previously, vitamins $\mathrm{E}$ and $\mathrm{C}$ have been administered separately in studies in which they were given orally to pregnant diabetic rats, yielding a decrease in the malformations induced by maternal diabetes (27-30). However, relatively high doses of the respective antioxidant were required for a positive effect on outcome of pregnancy. In another study, a cocktail with safflower oil, myo-inositol, and vitamin $E$ was able to reduce neural tube defects in embryos of diabetic rats (31). Vitamin $\mathrm{E}$ is a lipophilic antioxidant interfering with the chain reaction of lipid peroxidations (32). Vitamin $\mathrm{C}$ is a hydrophilic molecule that can scavenge several radicals, among them the hydroxyl radical. It is likely that vitamins $\mathrm{E}$ and $\mathrm{C}$ act in a synergistic manner, by vitamin $\mathrm{E}$ primarily being oxidized to the tocopheroxyl radical and then reduced back to tocopherol by vitamin C (33). Against this background we decided to use the lipophilic antioxidant vitamin $\mathrm{E}$ and the hydrophilic antioxidant vitamin $\mathrm{C}$ together as antioxidative protection in our rat model for diabetes-induced malformations.

The aim of this study was to determine whether a normalization of gestational outcome in diabetic rat pregnancy could be accomplished by addition of both vitamin $\mathrm{E}$ and vitamin $\mathrm{C}$ to the maternal diet. We also wanted to investigate whether normalization of the outcome could be achieved by the combined treatment at a lower total antioxidant dose than that of the individual vitamins. Along with the morphologic evaluation, we investigated variables for oxidatively modified lipids (TBARS) and proteins (carbonylated proteins) to estimate the efficiency of the treatment.

\section{METHODS}

Animals. Female Sprague Dawley rats weighing approximately $250 \mathrm{~g}$ were made diabetic by i.v. injection of $40 \mathrm{mg} / \mathrm{kg}$ STZ (a kind gift from Pharmacia and Upjohn, Kalamazoo, MI, U.S.A.). The rats were housed at the Laboratory Animal Resources of the Biomedical Center in Uppsala and were subjected to a 12-h dark/12-h light cycle. Blood glucose was measured (Glucose Analyzer 2, Beckman Instruments, Fullerton, CA, U.S.A.) in tail vein blood $1 \mathrm{wk}$ after STZ injection. Diabetes was defined as a blood glucose concentration $>20$ $\mathrm{mM}$. The rats were then mated overnight with normal male rats of the same strain; d 0 of pregnancy was defined as the day sperm in vaginal smear occurred. Powdered food was prepared from the commercial food pellet R36 (Lactamin AB, Stockholm, Sweden). Vitamin-supplemented food was prepared by blending DL- $\alpha$-tocopherol hydrogen succinate (E. Merck, Darmstadt, Germany) and sodium L $(+)$-ascorbate (Prolabo, Fontenay, France) into the powdered food. The vitaminsupplemented food was used the same day or the day after preparation, in which case it was stored in air-tight sealed plastic bags in $8^{\circ} \mathrm{C}$ in darkness overnight. All rats had free access to tap water.
The rats were either normal (no STZ injection; N) or manifestly diabetic (MD). Each of these groups was divided into three subgroups, such that one group received unsupplemented powdered food and the other groups received powdered food supplemented with $0.5 \%$ vitamin $\mathrm{E}$ and $1 \%$ vitamin $\mathrm{C}(\mathrm{wt} / \mathrm{wt})$ or $2 \%$ vitamin $\mathrm{E}$ and $4 \%$ vitamin $\mathrm{C}$. The supplemented groups are henceforth denoted $0.5+1$ and $2+4$, respectively, prefixed by $\mathrm{N}$ to denote normal mothers or MD for manifestly diabetic mothers. The diet with powdered food was started a few days before mating. At d 20 of pregnancy the rats were killed; they were anesthetized with ether, and blood was drawn into heparinized tubes from the abdominal aorta. The tubes were centrifuged at $1500 \times g$ for 10 min to obtain plasma, which was immediately frozen in liquid nitrogen and thereafter stored at $-135^{\circ} \mathrm{C}$. Maternal livers were weighed, cut into pieces, and frozen in liquid nitrogen. The fetuses and their placentas were dissected from the uterus and inspected for gross morphologic abnormalities. Mandibular malformations, i.e. micrognathia and agnathia, were most commonly observed. Dead fetuses were termed resorptions. Resorptions with a weight $>0.1 \mathrm{~g}$ were termed large, and those with a weight $\leq 0.1 \mathrm{~g}$, small resorptions; the large resorptions had a fetus-like appearance, whereas the small resorptions were small lumps of unorganized tissue. The proportion of resorptions was calculated with respect to the total number of implantations per litter. The share of malformed fetuses was calculated as a percentage of the total number of live fetuses in the litter. The fetuses and their placentas were weighed; four placentas from each litter were frozen in liquid nitrogen and stored at $-135^{\circ} \mathrm{C}$. From the same four fetuses the livers were dissected, weighed, and stored until biochemical analysis (see following). The tissue was thawed and homogenized in ice-cold distilled water at a concentration of $0.2 \mathrm{~g} / \mathrm{mL}$ and thereafter kept on ice.

Measurement of $\alpha$-tocopherol. $\alpha$-Tocopherol was measured as described by Simán and Eriksson (29). Briefly, $500 \mu \mathrm{L}$ of tissue homogenate or plasma was mixed with $500 \mu \mathrm{L}$ of methanol (E. Merck). Two milliliters of hexane was added, and the samples were manually shaken for $3 \mathrm{~min}$, then centrifuged at $1500 \times g$ for $10 \mathrm{~min}$ and the hexane phase collected. Fetal liver samples were concentrated 10-fold by drying under a nitrogen gas stream. The samples were separated with HPLC using a Spherisorb amino column $(4.6 \times 250 \mathrm{~mm}$, Phase Separation, Deeside, U.K.). The system was isocratic with isooctane/tert-butyl-methyl-ether/methanol (75 vol $/ 25 \mathrm{vol} / 5$ vol) as the mobile phase and a flow of $1 \mathrm{~mL} / \mathrm{min}$. The effluent was analyzed fluorometrically with an excitation wavelength of $295 \mathrm{~nm}$ and emission wavelength of $327 \mathrm{~nm}$. The fluorometer was a Shimadzu RF-10A (Shimadzu Corporation, Kyoto, Japan). The sample values were compared with values of standard samples prepared from $\alpha$-tocopherol (E. Merck).

Measurement of ascorbic acid. Ascorbic acid analysis was performed as described by Jagota and Dani (34). Standard samples were prepared in distilled water from ascorbic acid (E. Merck). Two hundred microliters of plasma or tissue homogenate was precipitated on ice with $800 \mu \mathrm{L}$ of trichloroacetic acid (E. Merck) for $5 \mathrm{~min}$ and then centrifuged at 12,000 $\times g$ for $5 \mathrm{~min}$. Five hundred microliters of the supernatant was subsequently diluted with distilled water to $2 \mathrm{~mL}$. Two hun- 
dred microliters of Folin-Ciocalteaus solution (E. Merck), diluted 1:10 in distilled water, was added to the samples, which were then immediately mixed. After $10 \mathrm{~min}$ the absorbance at $760 \mathrm{~nm}$ was measured using a Beckman DU-65 spectrophotometer (Beckman Instruments).

Measurement of TBARS. TBARS were determined fluorometrically after boiling samples with thiobarbituric acid. Two hundred microliters of plasma or tissue homogenate of maternal livers or $20 \mu \mathrm{L}$ of homogenate of fetal livers was heated to $97^{\circ} \mathrm{C}$ for 60 min together with $750 \mu \mathrm{L}$ of $0.19 \mathrm{mM} \mathrm{H}_{3} \mathrm{PO}_{4}$. Standard samples were prepared from malondialdehyde-bis(diethylacetal) (Merck-Schuchart, Schuchart, Germany). The samples were then precipitated with a mix of methanol and 1 $\mathrm{M} \mathrm{NaOH}$ (91:9) and centrifuged at 12,000 $\mathrm{g}$ for $5 \mathrm{~min}$. Fluorescence was measured on the supernatant, with an excitation wavelength of $532 \mathrm{~nm}$ and an emission wavelength of $553 \mathrm{~nm}$, using a Perkin-Elmer LS 5B luminescence spectrophotometer (Perkin-Elmer/Cetus, Norwalk, CT, U.S.A.).

Measurement of protein carbonylation. The fetal livers were sonicated in ice-cold phosphate buffer, $\mathrm{pH} \mathrm{7.2,} \mathrm{and} \mathrm{the}$ sonicates were then treated according to the instructions of the OxyBlot Oxidized Protein Detection Kit (Oncor, Gaithersburg, $\mathrm{MD}$, U.S.A.). Briefly, the carbonyl groups were derivatized to 2,4-dinitrophenylhydrazone using 2,4-dinitrophenylhydrazine by incubation of the samples with 2,4-dinitrophenylhydrazine for $15 \mathrm{~min}$. A neutralization solution containing $\beta$-mercaptoethanol was then added to the samples to stop the derivatization. The samples were separated on $11 \%$ polyacrylamide gels. Western blots were performed with all four groups (N, MD, MD 0.5+1, and MD 2+4) represented on each gel. BSA (ICN Biomedicals Inc., Aurora, OH, U.S.A.) was used to block the filters overnight. The filters were incubated for $1 \mathrm{~h}$ in each of primary (against hydrazone groups) and secondary antibodies and washed three times in PBS-Tween after each incubation. Chemiluminescence reactions were performed, and Kodak Biomax MR (Eastman Kodak Company, Rochester, NY, U.S.A.) films were exposed for $2 \mathrm{~min}$. Thereafter, the filters were stained for proteins with amido-black $(0.5 \%$ naphthol blue black, $50 \%$ methanol, $10 \%$ acetic acid), and both filters and films were scanned in a densitometer. A ratio of OxyBlot to protein was calculated, and the values for each sample were expressed as the percentage of the ratio of the sample to the ratio of the mean of all samples on that gel, containing one sample from each experimental group (N, MD 2+4, MD $0.5+1$, and MD).

Statistical analysis. Analysis of variance with Bonferroni/ Dunn's post hoc test and $\chi^{2}$ statistics with Fisher's exact $p$ value were used as applicable. A differences between means was considered to be significant when $p<0.05$. The analyses were performed using the Statview (SAS Institute Inc., Cary, NC, U.S.A.) software for Macintosh computers.

The Guide for the Care and Use of Laboratory Animals (National Institutes of Health publication 85-23, revised 1985) was followed, and all animal experimental procedures were approved by the Animal Ethics Committee of the Medical Faculty of Uppsala University.

\section{RESULTS}

Blood glucose and body weights. Maternal plasma glucose levels at gestational d 20 remained increased in the MD group, and no effect of vitamin treatment was seen in either the $\mathrm{N}$ or the MD groups. STZ-induced diabetes caused maternal weights to decrease (Table 1), and vitamin treatment in the diabetic groups partially restored this decrease. Maternal liver weights were not significantly affected by either diabetes or vitamin treatment (Table 1). A 30\% increase in placental weight was induced by maternal diabetes, which was not affected by vitamin treatment (Table 1). Maternal diabetes reduced fetal weights at gestational d 20 by approximately $35 \%$ (Table 1), and the fetal weights were partially restored in both of the vitamin-treated groups. The same pattern was noted for the fetal liver weights.

Fetal gross morphology. No cases of micrognathia were found in the $\mathrm{N}$ offspring, and the resorption rate was aproximately $5 \%$ in all $\mathrm{N}$ groups (Fig. 1). In the MD groups, on the other hand, we found $23 \%$ malformations and $32 \%$ resorptions, figures that were successively decreased by low-dose (13 and $20 \%$, respectively) and high-dose (9 and 13\%, respectively) antioxidant treatment (Fig. 1). In the low-dose group, however, both malformation and resorption rates were higher than in the $\mathrm{N}$ group. In the high-dose group the resorption rate was indistinguishable from that of the control group (Fig. 1). Figure 2 displays the distribution of all fetuses in each group as the rate of normal fetuses, resorptions (small and large), and malformations. No large resorptions were seen in the nondiabetic groups, whereas they constituted two thirds of the resorptions and $>20 \%$ of the implantations in the MD group (Fig. 2). The rate of large resorptions decreased in the diabetic groups with increasing vitamin dose to $9 \%$ in the MD $2+4$ group (Fig. 2). The rate of small resorptions did not vary among the groups and appeared largely unrelated to the maternal metabolic state.

Table 2 displays the morphologic outcome on a per litter basis compared with what has been seen in earlier studies in

Table 1. Maternal plasma glucose and maternal and fetal weights and liver weights

\begin{tabular}{|c|c|c|c|c|c|c|c|}
\hline Group & $n$ & $\begin{array}{c}\text { Plasma } \\
\text { glucose } \\
(\mathrm{mM})\end{array}$ & $\begin{array}{c}\text { Maternal } \\
\text { weight }(\mathrm{g})\end{array}$ & $\begin{array}{l}\text { Maternal liver } \\
\text { weight }(\mathrm{g})\end{array}$ & $\begin{array}{c}\text { Placental } \\
\text { weight }(\mathrm{g})\end{array}$ & $\begin{array}{l}\text { Fetal weight } \\
(\mathrm{g})\end{array}$ & $\begin{array}{l}\text { Fetal liver } \\
\text { weight }(\mathrm{g})\end{array}$ \\
\hline $\mathrm{N}$ & 5 & $4.8 \pm 0.8$ & $376 \pm 16$ & $12.6 \pm 0.8$ & $0.54 \pm 0.02$ & $3.5 \pm 0.1$ & $0.24 \pm 0.02$ \\
\hline $\mathrm{N} 2+4$ & 4 & $5.2 \pm 0.4$ & $353 \pm 14$ & $12.3 \pm 1.5$ & $0.49 \pm 0.02$ & $3.4 \pm 0.04$ & $0.21 \pm 0.01$ \\
\hline MD & 13 & $29.6 \pm 3.6^{*}$ & $276 \pm 7^{*}$ & $12.9 \pm 0.5$ & $0.64 \pm 0.02 *$ & $2.3 \pm 0.1^{*}$ & $0.14 \pm 0.01 *$ \\
\hline MD $0.5+1$ & 13 & $28.2 \pm 2.4^{*}$ & $312 \pm 8 * \dagger$ & $14.4 \pm 0.5$ & $0.64 \pm 0.02 *$ & $2.6 \pm 0.1^{*}$ & $0.17 \pm 0.01 *$ \\
\hline
\end{tabular}

Values are given as mean \pm SEM. * Significant difference from $N$ group; $\uparrow$ Significant difference from MD group (ANOVA). 


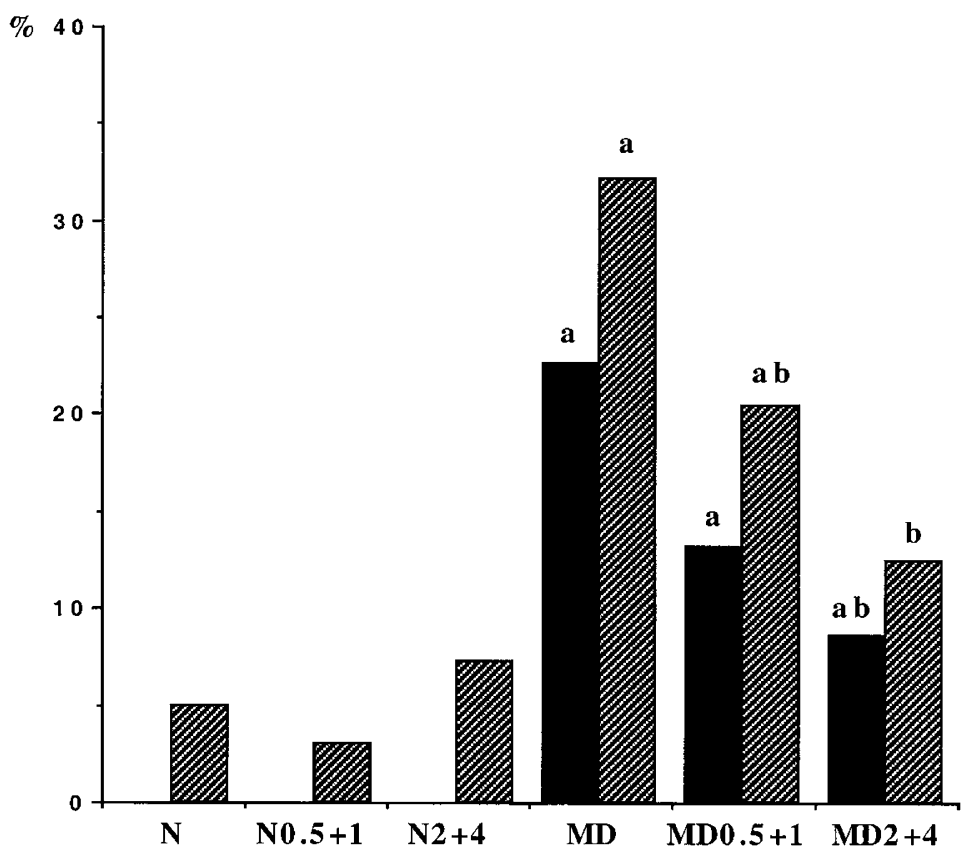

Malformations

Z Resorptions

Figure 1. Morphologic outcome as percent of the total number of implantations (resorptions) and living fetuses (malformations) at gestational $\mathrm{d} 20$ in pregnancies of $\mathrm{N}$ and $\mathrm{MD}$ rats. $a$, significant difference from $\mathrm{N}$ group; $b$, significant difference from MD group.

our laboratory using either only vitamin E (29) or only vitamin C (30) supplementation. Notably, the results were very similar among the studies with regard to the rates of resorptions and malformations. Combined treatment with both vitamins $\mathrm{E}$ and $\mathrm{C}$ in the present study decreased resorption rates in the MD group to the same extent as in Simán and Eriksson (29) using vitamin E alone (Table 2).

Biochemical measurements in the pregnant rats. Vitamin $\mathrm{E}$ levels in maternal plasma were not affected by diabetes in the unsupplemented groups (Table 3). Vitamin treatment increased the concentrations of vitamin $\mathrm{E}$ in plasma of diabetic rats and tended to do so in the nondiabetic groups. Plasma vitamin C concentrations were not altered by diabetes; the MD $0.5+1$ and MD 2+4 groups had higher concentrations than the MD group (Table 3). No significant differences in the TBARS concentrations in plasma were noted among any of the groups (Table 3); generally, however, the concentrations tended to be higher in the diabetic group than in the nondiabetic groups. In maternal livers, diabetes induced no difference in vitamin $\mathrm{E}$ concentrations (Table 3). Vitamin treatment did, however, increase the concentrations in a dose-dependent manner in both the nondiabetic and diabetic groups (Table 3). Vitamin $\mathrm{C}$ concentrations in maternal livers were increased by vitamin supplementation but were not affected by diabetes. In livers of the $\mathrm{N}$ group, the concentration of TBARS was paradoxically higher than in any of the other groups (Table 3); no other differences were seen for the concentration of TBARS in maternal livers.

Biochemical measurements in the fetuses. Vitamin E concentration in fetal livers was not altered by maternal diabetes (Fig. 3, Top). Maternal vitamin supplementation increased the

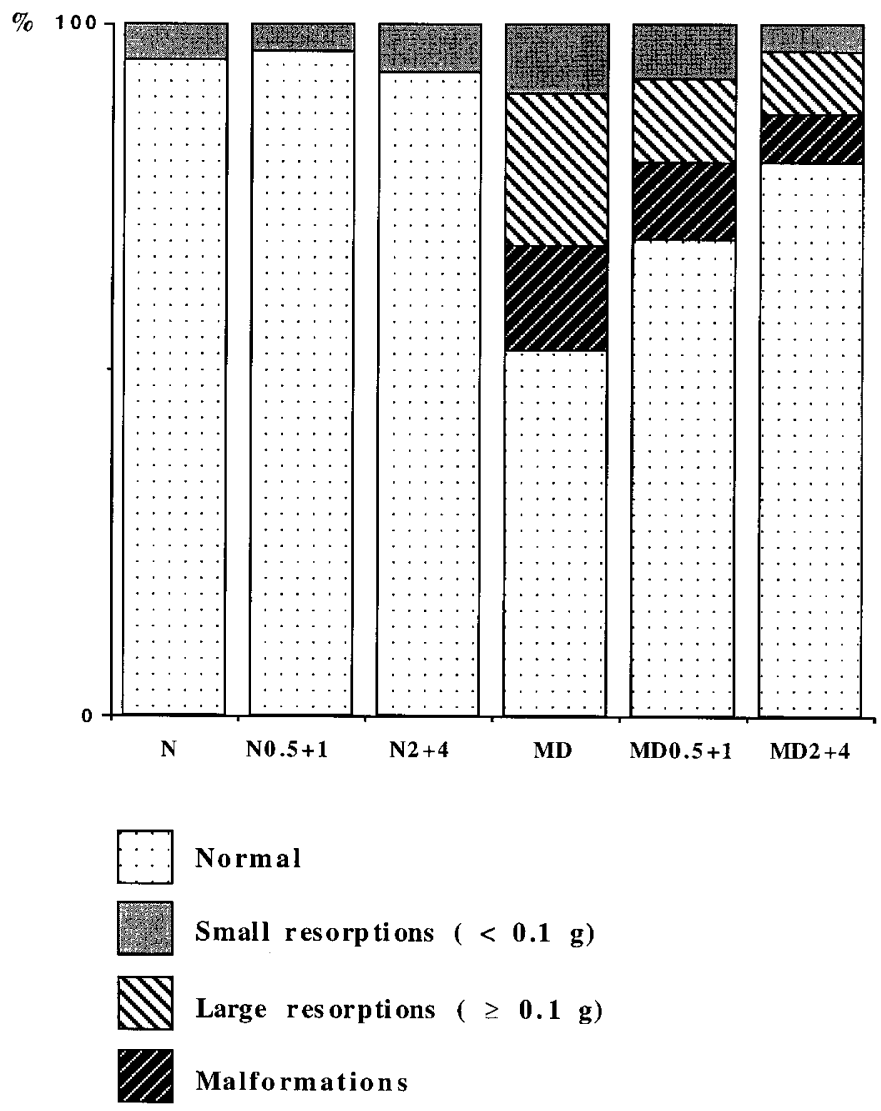

Figure 2. Distribution of morphologic outcome of all implantation in each group at gestational d 20 in pregnancies of $\mathrm{N}$ and $\mathrm{MD}$ rats. The entire bar represents $100 \%$ of implantations. Large resorptions are those with a wet weight $\geq 0.1 \mathrm{~g}$, small resorptions weighed $<0.1 \mathrm{~g}$. 


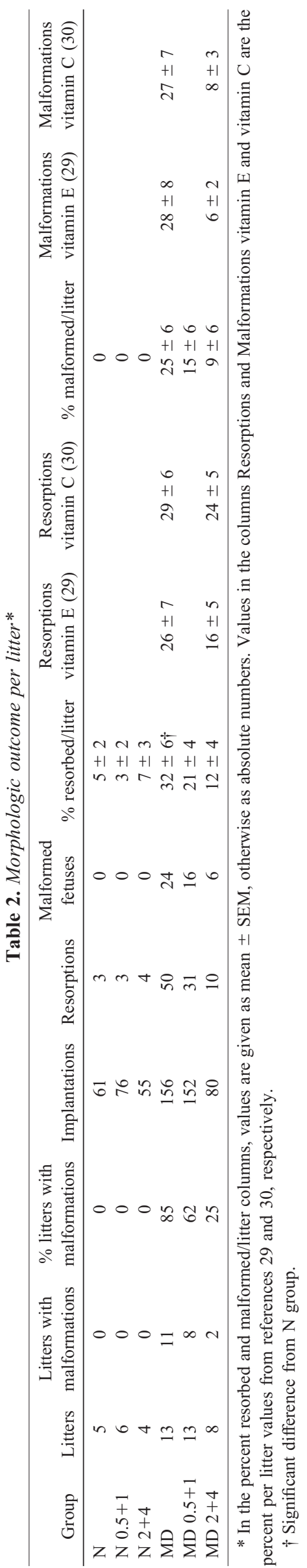

vitamin $\mathrm{E}$ content in fetal livers in the MD groups. Maternal diabetes did not alter fetal liver concentration of vitamin C; vitamin treatment raised this concentration in both normal and diabetic groups (Fig. 3, Middle). Fetal TBARS concentration was increased more than four times by maternal diabetes; both low- and high-dose antioxidant treatment reduced the TBARS concentrations back to normal levels (Fig. 3, Right).

A representative blot of the protein carbonylation experiment is depicted in Figure 4 (Left). Protein carbonylation was increased in the MD group compared with the $\mathrm{N}$ group, and maternal antioxidant treatment normalized the values in the high-dose group (Fig. 4, Right). In the MD group, the protein carbonylation values tended to be somewhat higher in the livers of malformed fetuses than in the livers of nonmalformed fetuses $(140 \pm 16$ versus $112 \pm 8$, expressed as percent of value for $\mathrm{N}$ liver on the same gel; mean $\pm \mathrm{SEM}$ ). No statistical difference was achieved ( $n=4$ in both groups).

\section{DISCUSSION}

We have investigated the effect of combined treatment with the lipid-soluble antioxidant $\alpha$-tocopherol and the watersoluble antioxidant ascorbate on the morphologic and biochemical outcome of diabetic rat pregnancy. The malformation and resorption rates were greatly reduced in the high-dose group, whereas in the low-dose group the outcome was intermediate to that of the MD and MD 2+4 groups. However, the combination therapy did not further improve the fetal outcome compared with that achieved by administering the vitamins individually, as previously reported $(29,30)$. These results may indicate that the doses of the individual antioxidants, rather than the added total molar dose of the antioxidants, determine the protective effect against diabetic embryopathy. As a consequence, attempts to completely normalize fetal outcome in diabetic pregnancy may have to include balanced mixtures of antioxidants and other antiteratogenic substances.

When resorptions were sorted by weight, we found approximately $5-10 \%$ of small resorptions $(<0.1 \mathrm{~g})$ in all groups. In contrast, we also found a population of large resorptions $(\geq 0.1$ g), which appeared exclusively in the diabetic groups and decreased in rate with higher dose of added vitamins. It appears likely that the larger malformations occurred during the later part of gestation, whereas the smaller resorptions were induced earlier. Evidently a large portion of late resorptions were induced by maternal diabetes and were dose dependently decreased by vitamin treatment, with the largest difference between the MD and MD $0.5+1$ groups. The cause of these late resorptions may be found in the increased rate of advanced heart malformations seen in experimental diabetic pregnancy (35).

Protein carbonyl groups are introduced via oxidation of proteins and can be used as markers for oxidatively modified proteins (36). By measuring protein carbonylation, a gradual reduction of the diabetes-induced protein damage in fetal livers was noted with increasing dosage of the administered antioxidants. Lipid oxidation in the fetal livers, as estimated with TBARS, was completely normalized already at the low dose of treatment, thus indicating that the combined vitamin $\mathrm{E}$ and $\mathrm{C}$ 
Table 3. Maternal biochemical data

\begin{tabular}{|c|c|c|c|c|c|c|c|}
\hline Group & $n$ & $\begin{array}{l}\text { Plasma vitamin E } \\
\qquad(\mu \mathrm{g} / \mathrm{mL})\end{array}$ & $\begin{array}{c}\text { Plasma vitamin } \mathrm{C} \\
(\mu \mathrm{g} / \mathrm{mL})\end{array}$ & $\begin{array}{c}\text { Plasma TBARS } \\
(\mu \mathrm{M})\end{array}$ & $\begin{array}{l}\text { Liver vitamin } \mathrm{E} \\
\qquad(\mu \mathrm{g} / \mathrm{g})\end{array}$ & $\begin{array}{l}\text { Liver vitamin } \mathrm{C} \\
(\mu \mathrm{g} / \mathrm{g})\end{array}$ & $\begin{array}{l}\text { Liver TBARS } \\
(\mathrm{nmol} / \mathrm{g})\end{array}$ \\
\hline $\mathrm{N}$ & 5 & $7 \pm 3$ & $15 \pm 5$ & $6 \pm 1$ & $21 \pm 5$ & $172 \pm 12$ & $42 \pm 4$ \\
\hline $\mathrm{N} 0.5+1$ & 6 & $8 \pm 1$ & $15 \pm 2$ & $3 \pm 1$ & $139 \pm 22 *$ & $358 \pm 24 *$ & $27 \pm 1^{*}$ \\
\hline MD & 13 & $6 \pm 1$ & $11 \pm 2$ & $16 \pm 8$ & $26 \pm 3$ & $174 \pm 17$ & $27 \pm 16^{*}$ \\
\hline MD $0.5+1$ & 13 & $21 \pm 3 * \dagger$ & $20 \pm 3 \dagger$ & $8 \pm 2$ & $253 \pm 19 * \dagger$ & $336 \pm 7^{* \dagger}$ & $26 \pm 1^{*}$ \\
\hline MD $2+4$ & 8 & $25 \pm 2 * \dagger$ & $30 \pm 2 * \dagger$ & $11 \pm 7$ & $364 \pm 33 * t t$ & $370 \pm 14 * \dagger$ & $25 \pm 2^{*}$ \\
\hline
\end{tabular}

Values are given as mean \pm SEM. * Significant difference from $\mathrm{N}$ group. $\dagger$ Significant difference from MD group. $\ddagger$ Significant difference from low-dose treated group of mothers with the same health status ( $\mathrm{N}$ or MD).
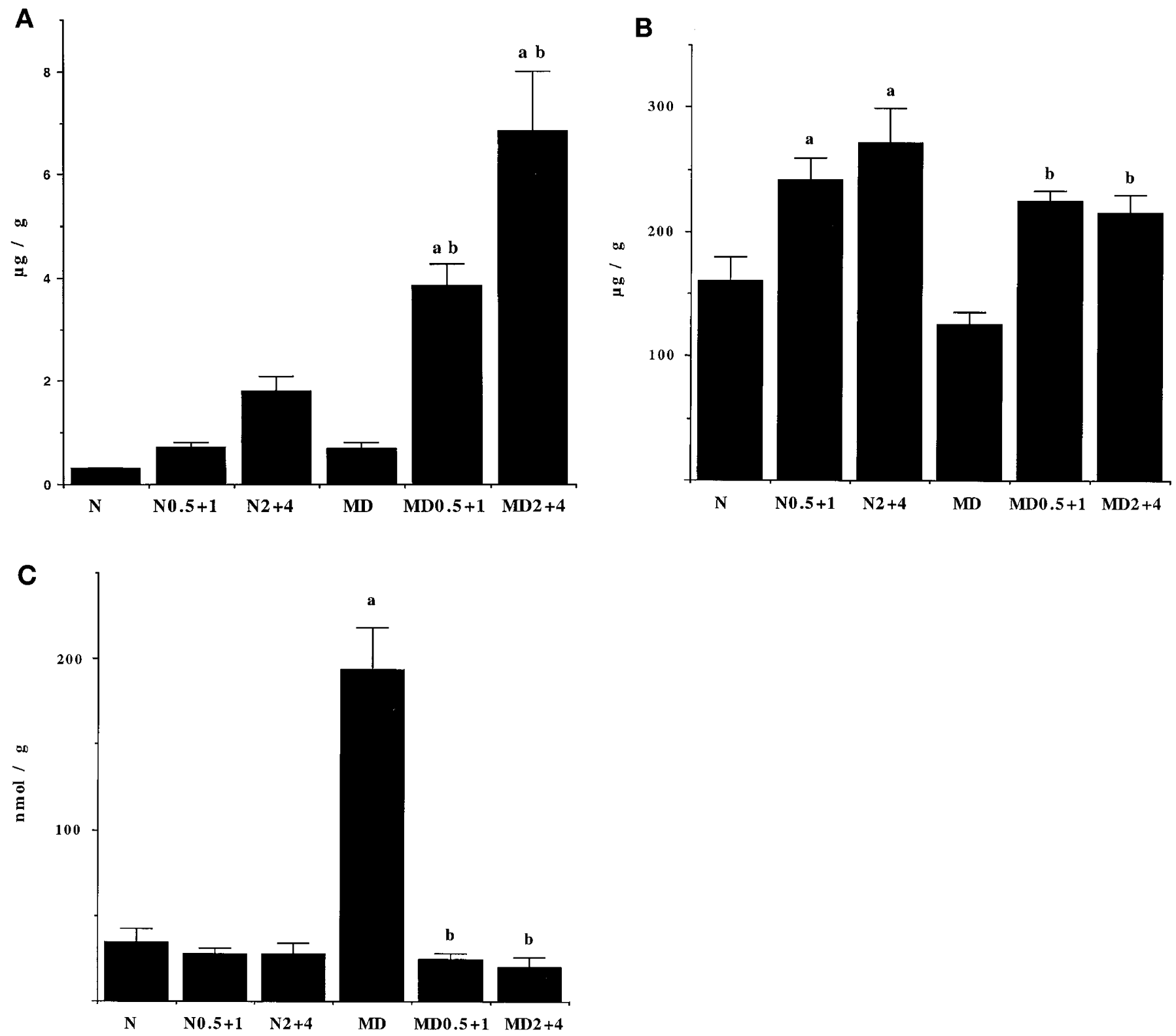

Figure 3. Concentration of $\alpha$-tocopherol $(A)$, ascorbic acid $(B)$, and TBARS $(C)$ in fetal livers at gestational d 20 in pregnancies of $\mathrm{N}$ and MD rats. Values are given as mean \pm SEM. $a$, significant difference from $\mathrm{N}$ group; $b$, significant difference from MD group.

treatment was more efficient in the lipid fraction of the cell. Interestingly, the degree of morphologic damage followed the carbonylation data more closely than the TBARS. This may suggest that a major part of the teratogenic action of diabetes occurs via protein damage. However, it should be noted that malformations are induced early in pregnancy and, most likely, in nonhepatic cells.

The weights of the mother, fetuses, and fetal livers were all decreased by maternal diabetes and partially restored by antioxidative treatment. The severity of diabetes, estimated as 
A

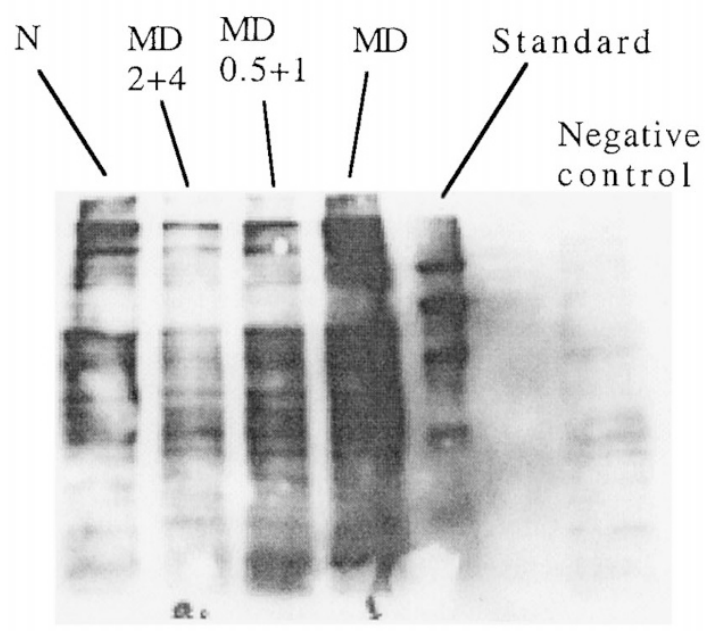

B

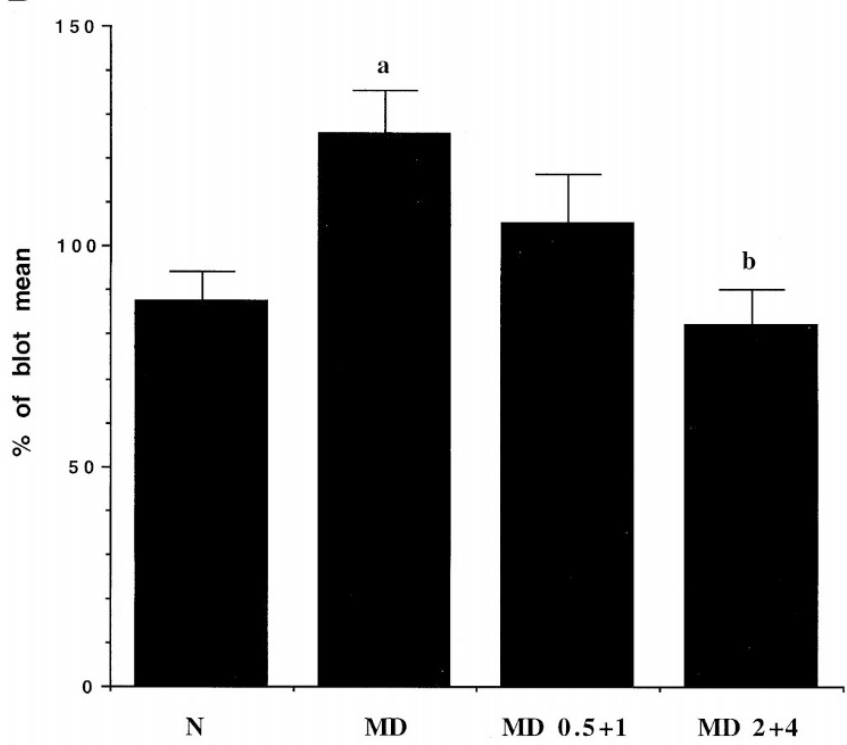

Figure 4. $A$, representative OxyBlot with a standard of dintrophenylated proteins. $B$, ratios of carbonylated proteins to total protein amounts in fetal livers. Values are expressed as mean \pm SEM. The values on each gel are normalized to a mean of $100 \%$. a, significant difference from $\mathrm{N}$ group; $b$, significant difference from MD group; $n=8$ in all experimental groups.

plasma glucose concentration, was not affected by the vitamin supplementation. Thus, the antioxidative treatment protected the pregnant rats and their offspring from the weight loss caused by the STZ-induced diabetes without protecting against the diabetes per se. These results are in line with previous data using vitamin $\mathrm{E}$ (29), whereas no positive effect was noted on fetal weight using vitamin C (30).

Vitamin $\mathrm{E}$ and vitamin $\mathrm{C}$ concentrations increased markedly in maternal plasma when these antioxidants were added to the food of diabetic rats whereas no significant increase could be detected in the plasma of normal rats. This could be related to increased food intake in the diabetic rats; however, this was not measured in this study. TBARS levels in maternal plasma were not significantly altered by either diabetes or vitamin treatment; this may be related to rapid clearing of peroxides from the circulation (37). The vitamin concentrations in maternal livers increased with the doses given in both $\mathrm{N}$ and MD rats. In maternal liver, a paradoxically high level of TBARS was detected in the $\mathrm{N}$ group. No satisfying explanation for this peculiarity seems obvious.

Diabetes did not affect the vitamin levels in fetal livers of the unsupplemented rats, despite the high TBARS levels in the MD fetal livers. This may be related to a high initial abundance of vitamin $\mathrm{E}$ in the MD livers because of a higher lipid content (38). The vitamin E content also increased more drastically in the supplemented diabetic groups than in the control groups, a fact that is probably also caused by the larger lipid contents in diabetic livers (38). In contrast to vitamin $\mathrm{E}$, vitamin $\mathrm{C}$ content in fetal livers increased in the same range in supplemented groups with or without diabetes. Thus, as found in previous studies $(29,30)$, maternally administered vitamins $\mathrm{E}$ and $\mathrm{C}$ reach the fetus in significant amounts.

The antioxidant doses used in this study are high, $2 \%$ vitamin E corresponding to approximately $2 \mathrm{~g} / \mathrm{kg}$ per day, and a decreased dose seems to result in decreased protection of the offspring against malformations. The necessity of high-dose treatment, however, in this experimental setting could be related to the severity of the diabetic state of the female rats with plasma glucose levels of almost $30 \mathrm{mM}$. Also, the metabolic rate is much higher in the rat than in the human; the approximate relation between metabolic rate $(M)$ and weight $(W)$ is $M$ $=3.8 \times W^{-0.25}$ (39), meaning that the metabolic rate of a $60-\mathrm{kg}$ human would be about one fourth that of a $250 \mathrm{-g}$ rat. Considering the slower human metabolic rate and the fact that human diabetic mothers experience a more-controlled diabetic state, it could be expected that significantly lower doses of antioxidants could be used in future prevention studies in diabetic pregnancy. In this context, it is of interest to note that a combination of vitamins $\mathrm{E}$ and $\mathrm{C}$ has been shown to decrease the occurrence of preeclampsia in high-risk women at a daily dose of $400 \mathrm{IU}$ of vitamin $\mathrm{E}$ plus $1 \mathrm{~g}$ of vitamin C (40).

We have shown that dietary treatment of pregnant diabetic rats with a combination of the lipid-soluble antioxidant $\alpha$-tocopherol and the water-soluble ascorbate can, in fetal livers, fully restore diabetes-induced lipid peroxidation and dosedependently ameliorate protein carbonylation in the same tissue and improve gestational outcome. The effect on gestational outcome seems to depend more on the dose of the individual antioxidants than on the total molar dose. This indicates that dietary additions aiming to reduce diabetic embryopathy should be composed of an antioxidant mixed with other protective agents.

There is a consensus that ROS are involved in diabetesinduced congenital malformations and that antioxidants are useful in preventive treatment. The research has now reached the state of optimizing treatment design before proceeding to clinical trials. This report demonstrates the lack of potential benefits of combining different antioxidants.

Acknowledgments. The authors thank Lisbeth Sagulin for her skilled technical assistance.

\section{REFERENCES}

1. Kucera J 1971 Rate and type of congenital anomalies among offspring of diabetic women. J Reprod Med 7:61-70 
2. Pedersen JF, Mølsted-Pedersen L 1979 Early growth retardation in diabetic pregnancy. BMJ 4:1-5

3. Mills JL 1982 Malformations in infants of diabetic mothers. Teratology 25:385-394

4. Hanson U, Persson B, Thunell S 1990 Relationship between haemoglobin A1c in early type 1 (insulin-dependent) diabetic pregnancy and the occurrence of spontaneous abortion and fetal malformation in Sweden. Diabetologia 33:100-104

5. Nordström L, Spetz E, Wallström K, Walinder O 1998 Metabolic control and pregnancy outcome among women with insulin-dependent diabetes mellitus: a twelve-year follow-up in the country of Jamtland, Sweden. Acta Obstet Gynecol Scand 77:284-289

6. Casson I, Clarke C, Howard C, McKendrick O, Pennycook S, Pharoah P, Platt M, Stanisstreet M, van Velszen D, Walkinshaw S 1997 Outcomes of pregnancy in insulin dependent diabetic women: results of a five year population cohort study. BMJ 315:275-278

7. Hawthorne G, Robson S, Ryall EA, Sen D, Roberts SH, Ward Platt MP 1997 Prospective population based survey of outcome of pregnancy in diabetic women: results of the Northern Diabetic Pregnancy Audit. BMJ 315:279-281

8. von Kries R, Kimmerle R, Schmidt JE, Hachmeister A, Bohm O, Wolf HG 1997 Pregnancy outcome in mothers with pregestational diabetes: a population based study in North Rhine (Germany) from 1988 to 1993. Eur J Pediatr 156:963-967

9. Leslie RDG, Pyke DA, John PN, White JM 1978 Hemoglobin A1 in diabetic pregnancy. Lancet 2:958-959

10. Greene MF, Hare JW, Cloherty JP, Benacerraf BR, Soeldner JS 1989 First-trimester hemoglobin $\mathrm{A}_{1}$ and risk for major malformation and spontaneous abortion in diabetic pregnancy. Teratology 39:225-231

11. Sadler TW, Hunter ES, Wynn RE, Phillips LS 1989 Evidence for multifactorial origin if diabetes-induced embryopathies. Diabetes 38:70-74

12. Styrud J, Thunberg L, Nybacka O, Eriksson UJ 1995 Correlations between materna metabolism and deranged development in the offspring of normal and diabetic rats. Pediatr Res 37:343-353

13. Eriksson UJ 1988 Importance of genetic predisposition and maternal environment for the occurrence of congenital malformations in offspring of diabetic rats. Teratology $37: 365-374$

14. Otani H, Tanaka O, Tatewaki R, Naora H, Yoneyama T 1991 Diabetic environment and genetic predisposition as causes of congenital malformations in NOD mouse embryos. Diabetes 40:1245-1250

15. Oberley LW 1988 Free radicals and diabetes. Free Radic Biol Med 5:113-124

16. Baynes JW 1991 Role of oxidative stress in development of complications in diabetes. Diabetes 40:405-412

17. Baynes JW, Thorpe SR 1999 Role of oxidative stress in diabetic complications: a new perspective on an old paradigm. Diabetes 48:1-9

18. Eriksson UJ, Borg LAH 1991 Protection by free oxygen radical scavenging enzymes against glucose-induced embryonic malformations in vitro. Diabetologia 34:325-331

19. Eriksson UJ, Borg LA 1993 Diabetes and embryonic malformations: role of substrateinduced free-oxygen radical production for dysmorphogenesis in cultured rat embryos. Diabetes 42:411-419

20. Trocino RA, Akazawa S, Ishibashi M, Matsumoto K, Matsuo H, Yamamoto H, Goto S, Urata Y, Kondo T, Nagataki S 1995 Significance of glutathione depletion and oxidative stress in early embryogenesis in glucose-induced rat embryo culture. Diabetes 44:992-998

21. Sakamaki H, Akazawa S, Ishibashi M, Izumino K, Takino H, Yamasaki H, Yamaguchi Y, Goto S, Urata Y, Kondo T, Nagataki S 1999 Significance of glutathione- dependent antioxidant system in diabetes-induced embryonic malformations. Diabetes 48:1138-1144

22. Wentzel P, Welsh N, Eriksson UJ 1999 Developmental damage, increased lipid peroxidation, diminished cyclooxygenase-2 gene expression, and lowered $\mathrm{PGE}_{2}$ levels in rat embryos exposed to a diabetic environment. Diabetes 48:813-820

23. Jenkinson PC, Anderson D, Gangolli SD 1986 Malformations induced in cultured rat embryos by enzymically generated active oxygen species. Teratog Carcinog Mutagen 6:547-554

24. Anderson D, Francis AJ 1993 The modulating effects of antioxidants in rat embryos and Sertoli cells in culture. Basic Life Sci 61:189-200

25. Cederberg J, Eriksson UJ 1997 Decreased catalase activity in malformation-prone embryos of diabetic rats. Teratology 56:350-357

26. Cederberg J, Galli J, Luthman H, Eriksson UJ 2000 Increased mRNA levels of $\mathrm{Mn}-\mathrm{SOD}$ and catalase in embryos of diabetic rats from a malformation-resistant strain. Diabetes 49:101-107

27. Viana M, Herrera E, Bonet B 1996 Teratogenic effects of diabetes mellitus in the rat: prevention with vitamin E. Diabetologia 39:1041-1046

28. Sivan E, Reece EA, Wu YK, Homko CJ, Polansky M, Borenstein M 1996 Dietary vitamin $\mathrm{E}$ prophylaxis and diabetic embryopathy: morphologic and biochemical analysis. Am J Obstet Gynecol 175:793-799

29. Simán CM, Eriksson UJ 1997 Vitamin E decreases the occurrence of malformations in the offspring of diabetic rats. Diabetes 46:1054-1061

30. Simán CM, Eriksson UJ 1997 Malformations in the offspring of diabetic rats are prevented by supplementation of the maternal diet with vitamin C. Diabetologia 40:1416-1424

31. Reece EA, Wu Y-K 1997 Prevention of diabetic embryopathy in offspring of diabetic rats with use of a cocktail of deficient substrates and an antioxidant. Obstet Gynecol 176:790-798

32. Ingold KU 1961 Inhibition of the autoxidation of organic substances in the liquid phase. Chem Res 61:563-589

33. Tappel AL 1968 Will antioxidant nutrients slow aging processes? Geriatrics 23:97105

34. Jagota SK, Dani HM 1982 A new colorimetric technique for the estimation of vitamin C using Folin phenol reagent. Anal Biochem 127:178-182

35. Simán CM, Gittenberger-de Groot AC, Wisse B, Eriksson UJ 2000 Malformations in offspring of diabetic rats: morphometric analysis of neural crest-derived organs and effects of maternal vitamin E treatment. Teratology 61:355-367

36. Stadtman ER, Oliver CN 1991 Metal-catalyzed oxidation of proteins. J Biol Chem 266:2005-2008

37. Halliwell B, Chirico S 1993 Lipid peroxidation: its mechanism, measurement and significance. Am J Clin Nutr 57(suppl):715S-725S

38. Gupta D, Raju J, Prakash J, Baquer NZ 1999 Change in the lipid profile, lipogenic and related enzymes in the livers of experimental diabetic rats: effect of inulin and vanadate. Diabetes Res Clin Pract 46:1-7

39. Hau J, Poulsen OM 1988 Doses for laboratory animals based on metabolic rate. Scand J Lab Anim Sci 15:81-83

40. Chappell LC, Seed PT, Briley AL, Kelly FJ, Lee R, Hunt BJ, Parmar K, Bewley SJ, Shennan AH, Steer PJ, Poston L 1999 Effect of antioxidants on the occurrence of pre-eclampsia in women at increased risk: a randomised trial. Lancet 354:810-816 